Original Research

\title{
Using Windbreaks for Decreasing Lake and Reservoir Evaporation: A Case Study from Iran
}

\author{
Seyed Arman Hashemi Monfared ${ }^{1 *}$, Mehdi Rezapour ${ }^{2}$, Tahmineh Zhian ${ }^{1}$ \\ ${ }^{1}$ Department of Civil Engineering, University of Sistan and Baluchetan, Zahedan, Iran \\ ${ }^{2}$ Department of Civil Engineering, Chabahar Maritime University, Chabahar, Iran
}

Received: 16 December 2017

Accepted: 14 April 2018

\begin{abstract}
Evaporation from reservoirs is an important issue frequently occurring in dry, hot regions like Iran. Since the laboratory and field studies of evaporation control are difficult, time-consuming, and costly, and the investigation of various possible modes is not possible, numerical models with high capabilities are widely used to analyze the hydrological processes. This article aimed to investigate the effect of windbreaks on reducing evaporation of lakes and reservoirs in dry areas and determine the most optimal location and layout of windbreaks using the FLUENT model. Initial investigations showed that wind is the most important factor of evaporation in the Chahnimeh Region of Sistan, Iran. The results showed that if solid windbreaks with $25 \%$ casement (height of 2 and distance of $66 \mathrm{~m}$ ) are vertically installed in a northwesterly direction, evaporation can be effectively reduced. Although the use of wind breaks in Chahnimeh can help significantly reduce evaporation, it cannot be fully controlled. That is why diagonal windbreaks with 30,45 , and $60^{\circ}$ were designed to integrate the windbreaks with other evaporation control methods such as solar panels. The results showed that $60^{\circ}$ had the greatest amount of evaporation reduction and were integrated with other methods to control evaporation.
\end{abstract}

Keywords: evaporation control, wind speed, simulation, FLUENT numerical model

\section{Introduction}

The $21^{\text {st }}$ century is engaged with problems related to the steady increase in population, depletion of natural resources, environmental degradation, and limited resources. Resource managers and researchers must take certain measures for the optimal utilization and maintenance of natural resources for future generations.

*e-mail: hashemi@eng.usb.ac.ir
These measures are becoming more challenging on a daily basis. One of these is natural water resources. The amount and quality of water directly affects living, health, income levels, and the volume of crops and livestock [1]. One of the ways to waste water in different parts of the world is evaporation. Different methods such as physical-mechanical, chemical, and biological methods are used to control evaporation in order to control evaporation from reservoirs [2]. One of the physical methods of evaporation control for areas with high wind speeds is the use of wind tunnel walls. Wind is one of the main elements of every climate, and 
its changes can affect phenomena such as dust storms, earth erosion, and evapotranspiration [3]. Windbreak Technology is a tool to deal with these challenges. Windbreaks are structures used to control wind speed [4]. These structures can be artificial barriers or protective tree belts. These structures are used to control erosion, produce agricultural products, save energy consumption, develop the environment, manage waves and turbulence, etc. Reducing evaporation is one of the most important uses of windbreaks done through the change in wind velocity and direction and air turbulence. Therefore, the evaporation process indirectly influences at certain distances.

Numerous studies have been conducted to examine the effect of windbreaks on wind velocity. These studies have paid limited attention to the effect of windbreaks on the evaporation of small water resources [5]. Windbreak efficiency on wind velocity reduction depends on three important factors: height, porosity, and direction toward wind. Height is the most important factor in the windbreak structure because the length of the protected area in front of and behind the windbreak depends on windbreak height. The length of the protected area behind the windbreak generally depends on windbreak height $[6,7]$.

Porosity is another most popular factor that describes the internal structure of windbreaks. Porosity is the ratio of empty space area to the entire windbreak area. Porosity prevents air turbulence. If a solid windbreak is used, the minimum wind velocity moves towards the windbreak and air flow will pass over it. Air pressure increases around the porous windbreaks at the windward side; however, a low-pressure zone occurs in the leeward. Windward air pressure pushes the air forward inside and above the windbreak, while the low-pressure zone behind the windbreak pulls the passing air through the windbreak. If a very porous windbreak is used, the air flow in the quiet zone can change direction, leading to an eddy current [8-12]. In addition to height and porosity, which are effective in windbreak efficiency, maximum efficiency is claimed to be achieved when the barriers are perpendicularly located $[13,14]$.

Windbreaks have been used for many years as wind erosion in agricultural lands and dispersion of eroded particles, dust, and spray drift to nearby habitation [15, 16], and a huge tract of reclaimed land to prevent the generation and diffusion of dust from dry land [17]. The effectiveness of using windbreaks in agriculture is related to the reduced wind velocity. The advantages include the reduced effects of wind on plants, reduction of pathogens and pests, the reduction of pollutants, and high crop production performance [18, 19]. Also, Wind in open and urban areas can be controlled by a windbreak whose primary benefit is the reduction of wind velocity [20-22].

Natural windbreaks such as trees are very efficient barriers to high-velocity winds. The main factors that can affect the efficiency of a windbreak are tree height, width, tree arrangement, porosity, etc. [23].
In addition to the aforementioned factors, the type of plants as natural windbreak is of great importance in inhibiting wind velocity $[24,25]$. Wu (2015) compared the mean velocity behind two types of plants (AREMISIA and SALIX). Depending on the velocity, the shelter impact zone is different. According to the features, both of these plants can be effective in controlling the sand motion in dry regions [26]. Climate needs to be taken into account while selecting windbreaks because the water used by natural windbreaks influences the regional underground water. Therefore, an inappropriate system can lead to important consequences in dry regions [27]. As stated earlier, in addition to using windbreaks for controlling evaporation, erosion, and agriculture, they can be used in livestock and industrial and power plant installations as protection against wind velocity [28-31]. Extensive studies have been conducted in this regard. For example, a model was proposed by Viagiak (2003) to integrate windbreak shelter breaks into a geographic information system (GIS). Windbreak shelter is modeled in terms of friction velocity reduction, which is a function of wind speed and direction, distance from the barrier, windbreak height, porosity, width, and orientation. The model was first used in a study in an area with an extensive windbreak network in England. The windbreak features were recorded, including windbreak type, height, width, porosity, and location. In order to investigate the impact of the network, a windbreak network shelter index (SI) was suggested based on the average decline of the wind velocity in the study area. The network was found to provide an acceptable level of protection; however, windbreak distribution was not found to be optimal in terms of the wind vector distribution. The integration model has some limitations that should not be ignored. The most important limitation was simplification of the effects of multiple barriers and diagonal winds [32].

Yusaiyin and Tanaka (2009) studied the effect of windbreak width on tension force and bulk tension coefficient using 2D Navier-Stokes equations to show that wind tension force increases as windbreak width rises; however, bulk tension coefficient declines. Then they proposed a relationship between Bulk tension coefficient, windbreak width, and height. The results also show that windbreak width is effective in the location and extent of minimum wind speed. As windbreak width rises, wind speed declines by $15-22 \%$ [33].

Elastically supported windbreak panels were investigated by Giannoulis (2015) using CFD - static analytical model. The results were compared to panels of hinge support at their base. Elastic support field tests were performed using expansive springs, allowing rotation at base support in reaction to wind loading. Developed wind pressures were measured on the panels for various positions of equilibrium under different wind expansions. The results showed that the elastic support was responsible for significantly reducing the wind pressure and tensions on the windbreak [34]. 
This study investigates the extent of evaporation reduction through wind velocity control by artificial windbreaks from the reservoir and lake. Chahnimeh Reservoir in Zabol, Iran was selected as the study area. The reservoir consists of four natural organized pits that lie in the northern section of Hirmand River Delta in Sistan, Iran. The hydrologic data related to evaporation, temperature, humidity, and wind velocity are collected and analyzed statistically in SPSS, providing a linear relationship of evaporation with humidity, temperature, and wind velocity. The results of the analysis showed the importance and effect of wind velocity compared to other parameters on the evaporation in the region. A 2-D simulation was done in FLUENT to develop a model of wind flow on the reservoir surface with the windbreak obstacles. Since the dimensions are vast and the simulation is difficult, hydraulic similarity (Reynolds number) was employed to lower the size of the region. This prepares the ground for simulation. This simulation was aimed at determining the best windbreak height in order to control wind speed, prevent flow turbulence, and characterize the windbreak porosity effect on reduced wind velocity, the effect of windbreak angle compared to the horizon on the wind speed reduction, and the best solid and casement windbreak configuration.

\section{Materials and Methods}

\section{Numerical Model}

Computational fluid dynamics (CFD) models have the ability to simulate the wind flow effect around a fence in a fast and computationally efficient manner [35]. FLUENT is one of the most complete and widely used software packages in CFD. The ease of use and its frequent capabilities for solving flow analysis are why the software package is widely used in research and industry. FLUENT is an analytical tool for 2D and 3D flows using Navier-Stokes equations. If the flow is turbulent, the governing equations change into Reynolds equations. One-, two-, three-, four-, and five-equation models are then employed by the user. FLUENT solvents are based on the finite volume method [36]. The general form of equations is as follows:

Continuity equation

$$
\frac{\partial}{\partial t} \iiint_{\varphi} \rho d \varphi+\iint_{S} \rho \vec{V} \cdot \mathrm{d} \vec{S}=0
$$

\section{Momentum equation}

$$
\frac{\partial}{\partial t} \iiint_{\varphi} U d \varphi+\iint_{S} \vec{F} \cdot \mathrm{d} \vec{S}=\iint Q_{v} d \varphi+\iint_{S} Q_{S} \cdot \mathrm{d} \vec{S}
$$

$$
\begin{aligned}
& \text { Energy equation } \\
& \frac{\partial}{\partial t} \iiint_{\varphi} E_{t} d \varphi+\iint_{s} \overrightarrow{E_{t} v} \cdot \mathrm{d} \overrightarrow{\mathrm{s}}=\iiint_{\varphi}(\rho \overrightarrow{\dot{q}}+\rho \vec{f} \cdot \vec{v}) d \varphi
\end{aligned}
$$

Defined turbulence models in FLUENT are the SPALART-ALLMARAS single equation model, K- $\varepsilon$ and K- $\omega$ double equation model, TRANSITION K-KLOMEGA triple equation model, TRANSITION SST four-equation model, and REYNOLDS STRESS fiveequation model. In this study, we used K- $\varepsilon$, RNG for the solid windbreak and $\mathrm{k}-\omega, \mathrm{BSL}$ for casement windbreak turbulence model to model the wind flow. This is one of the commonly used two-equation models, which include two extra-energy equations for calculating the turbulence properties of the flow. The first transitional variable is kinetic turbulence energy $(\mathrm{K})$. The second transitional variable in this model is the loss of disturbance $(\varepsilon, \omega)$. $\mathrm{K}$ and $\varepsilon$ are determined as follows:

$$
\begin{gathered}
T_{i}=\frac{u^{\prime}}{u_{\text {ave }}} \cong 0.16\left(\operatorname{Re}_{D_{H}}\right)^{-1 / 8} \text { And } \quad K=\frac{3}{2}\left(\mathrm{u}_{\text {ave }} T_{i}\right)^{2} \\
\varepsilon=C_{\mu}^{3 / 4} \frac{k^{1.5}}{l} \quad \text { And } \quad l=0.07 L
\end{gathered}
$$

...where $\mathrm{U}_{\text {ave }}=$ average flow speed, $T=$ severity of turbulence, $\mathrm{C}_{\mathrm{M}}=$ experimental constant factor of $\mathrm{K}-\varepsilon$ disturbance model, considered $0.09,1=$ mixing length, and $\mathrm{L}=$ length of field.

\section{Study Area}

Sistan is among the regions with excessive events such as floods and droughts, giving unique characteristics to the region due to special hydraulichydrological and spatial conditions. Being in a closed catchment area, the complex hydraulic system of the Hirmand River and Hamoon Wetland, hydrological conditions governing Chahnimeh Reservoir, and 120-day winds blowing around the northwest over the course of the three months of the summer are responsible for recent draughts, dust increase, and air pollution. This has adversely affected the living condition. There are also other issues such as poor annual rainfall, high temperature, and soil with low permeability, groundwater resource constraints, and joint surface water resources with Afghanistan. Chahnimeh Reservoir is one of the most important resources of surface water in Sistan. Chahnimeh Reservoir consists of four natural pitches. It lies in northern Hirmand River Delta in the Iranian Sistan region with a latitude of $30^{\circ} 45^{\prime}$ and longitude of $61^{\circ} 38^{\prime}$ at average height of $500 \mathrm{~m}$ above sea level (Fig. 1). This reservoir forms a single-body waterfall during the high-water years, and in dry years it creates separate zones of water. With a maximum capacity of almost 630 million $\mathrm{m}^{3}$ and area of over $47 \mathrm{~km}^{2}$, Chahnimeh Reservoir is the water supply for Zabol, Zahedan, and other residential areas of Sistan. It also supplies the irrigation water for almost 8000 hectares of the region. In the northern area is an evaporation station. There are also two other stations 


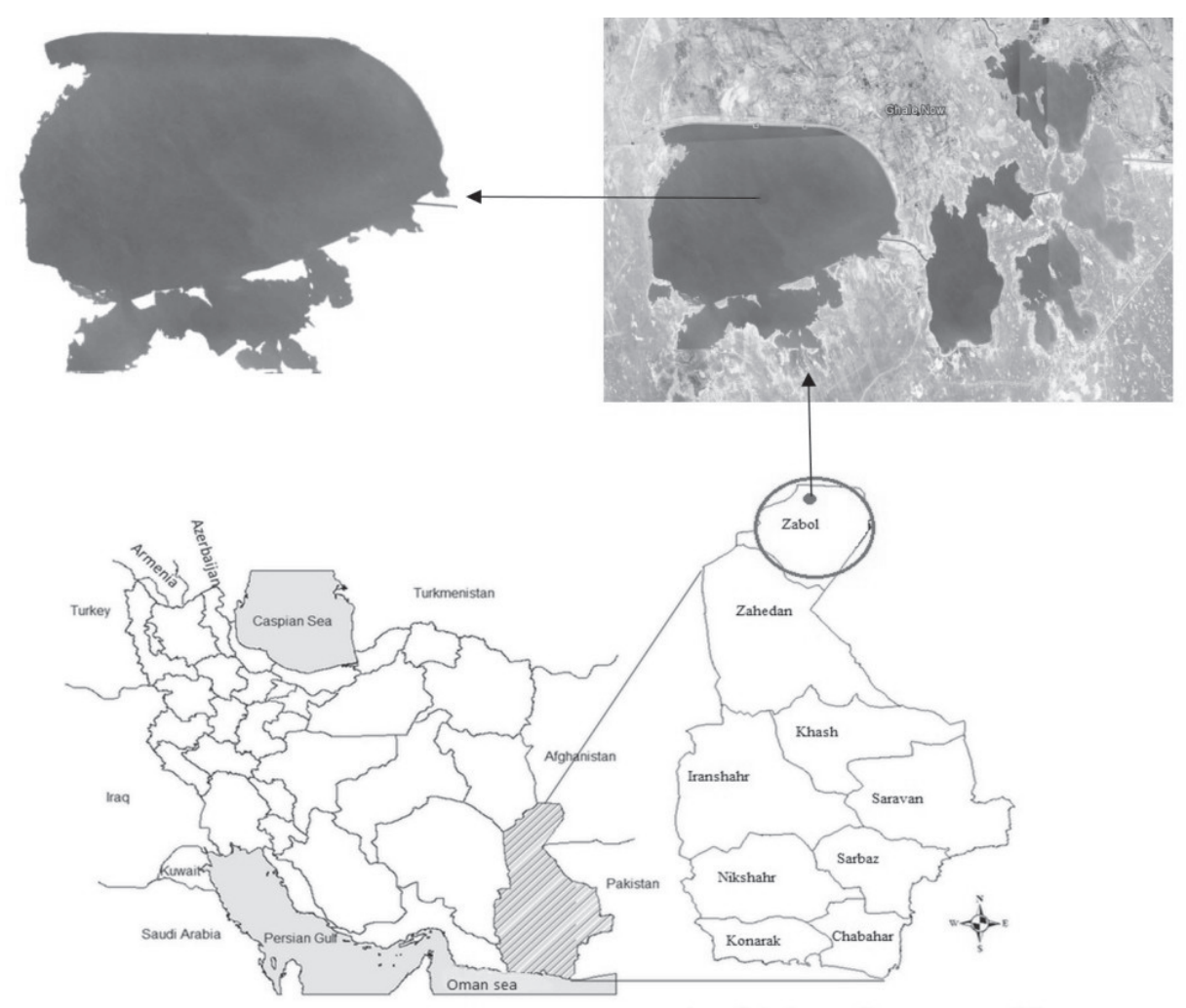

Fig. 1. Chahnimeh Reservoir 4 in southeastern Iran.

(Synoptic in Zahak and Evaporation in Zahak). They are $5 \mathrm{~km}$ north of the reservoir next to each other. The recorded statistics are considered appropriate for use in scientific studies [37].

\section{Model Simulation}

The first assumption is that wind is the most important factor of evaporation. The annual evaporation, wind velocity, temperature, and humidity of Zahak Meteorological Station were used. After statistically analyzing the data, linear multivariate regression was created. Eventually, the equation with the lowest standard error and greatest correlation was considered the final one:

$$
E=-1.452+(0.464 * T)+(0.686 * W)-(0.102 * M)
$$

...where $\mathrm{E}=$ evaporation $(\mathrm{mm}), \mathrm{T}=$ temperature (centigrade), $\mathrm{W}=$ wind speed $(\mathrm{m} / \mathrm{s})$, and $\mathrm{M}=$ relative moisture.

After determining the rational relationship between evaporation and temperature, and wind velocity and humidity, the windbreak system needs to be selected. According to the system, either artificial or natural (trees) windbreaks are used.

Natural windbreaks are dynamic systems changing and developing during their service life. These windbreaks must be constantly managed in order to be effective, to minimize the effect of insects and diseases, and to provide long-term optimal advantages. Also, the study by Smith et al. (1997) showed that natural windbreaks must supply the required water through underground tables or surface water. This is not possible in Sistan due to the water crisis. A long time is also required to grow them. On the other hand, these windbreaks are responsible for water loss through evaporation. Artificial windbreaks were used in this study due to the above-mentioned issues and regional climatic conditions.

In this section, 2D-simulation of Chahnimeh Reservoir was done after determining the windbreak in line with climatic conditions. Since the region is vast, simulation is difficult. Reynolds number is used to shrink the area. The 1/24 scale was used to make simulation possible. The next step is to build the model range. GAMBIT was used to impose the boundary conditions, mesh the computational field, and solve the flow field. The first stage is determining the appropriate model height. An appropriate height is one not affecting the wind-speed input. The study by Wang and Takle (1995) showed that the model height must be 8 times as much as the windbreak height. According to the first assumption for 3-m windbreak height becomes $0.125 \mathrm{~m}$ by $1 / 24$ scale. Therefore, the model height is $1 \mathrm{~m}$. In this study, the height was considered $2 \mathrm{~m}$ in order to ensure that height had no effect on wind velocity. The next parameter is model length. According to previous studies, the flow length must be $30 \mathrm{H}-50 \mathrm{H}$ after the windbreak. The length was considered $30 \mathrm{H}$ in 


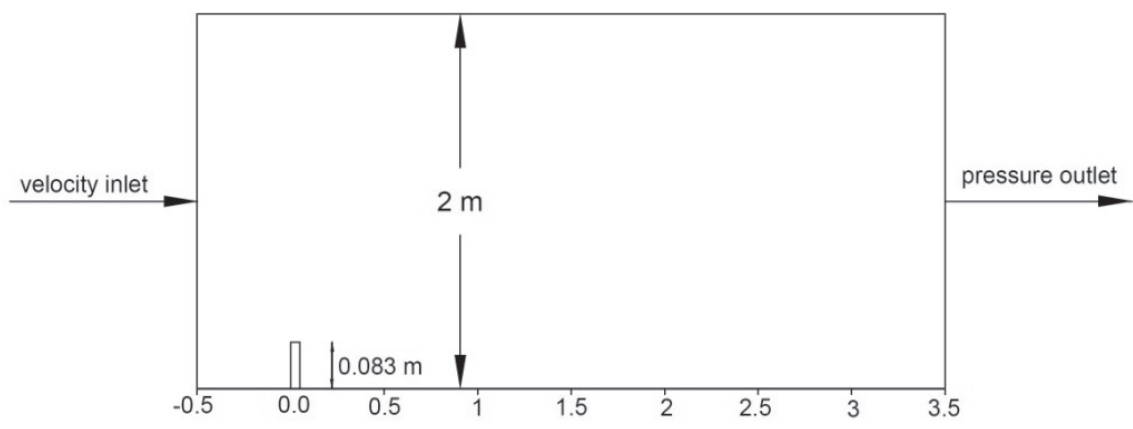

Fig. 2. The flow range and solid windbreak simulated in GAMBIT.

this study. After determining the flow range, boundary conditions must be imposed. Velocity inlet and pressure outlet were considered. Fig. 2 shows the flow in GAMBIT.

In the last stage, the model is meshed. The GAMBIT outlets are used for FLUENT inputs. It is essential to determine the input wind, type of fluid, fluid features, and type of turbulence equation in FLUENT. Maximum wind speed is $19 \mathrm{~m} / \mathrm{s}$. It is converted to $456 \mathrm{~m} / \mathrm{s}$ (1/24 scale). Therefore, we defined the wind velocity of $456 \mathrm{~m} / \mathrm{s}$ at the boundary conditions at the velocity inlet section.

In this study, as stated before, $\mathrm{K}-\varepsilon, \mathrm{RNG}$ for solid windbreak and $\mathrm{K}-\omega$, BSL for porous windbreak turbulence model was used to model the wind flow. The last step is solving. If the results are convergent, the selected mesh is appropriate; otherwise, the mesh needs to be changed and the question must be solved again. The procedure is done for $2,2.5,4$, and $5 \mathrm{~m}$ solid windbreaks. After simulating the solid windbreak, a casement windbreak is modeled. According to the studies in the past, we know that if the barrier is dense, air will pass over it. As a result, air turbulence is created on the wind leeward due to lower pressure. Therefore, in this method, compared to the relatively permeable windbreaks, an effective area is created on the leeward of the wind. Porous windbreaks have many
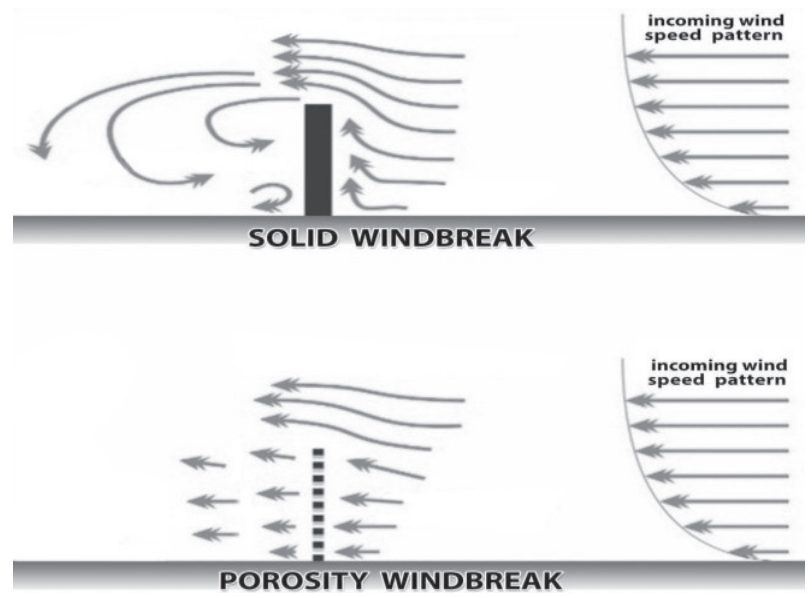

Fig. 3. Airflow changes for solid and porous windbreaks. advantages such as reduced vortex flow behind the windbreaks, declining turbulence, pressure behind the windbreaks, and velocity. As a result, greater distances can be considered between windbreaks. Fig. 3 shows the difference.

Past studies show that porous windbreaks were mainly used for wind erosion prevention, livestock protection, agriculture, etc. Since this article was aimed at reducing evaporation through wind control, porous windbreaks cannot be used. The proposed windbreaks have casement (the lower half of the windbreak is fully solid, while the upper half has casement). In this study, windbreaks with $10 \%, 15 \%, 20 \%, 25 \%$, and $30 \%$ casement were taken into account. Modeling windbreaks with casements are similar to those of solid windbreak simulation. The only difference lies in turbulence. $\mathrm{k}-\omega, \mathrm{BSL}$, and the turbulence model were used for windbreaks with casement. Layout and distance between windbreaks are important factors.

After modeling vertical windbreaks, diagonal windbreaks are modeled. The angles are 30, 45, and 60 . Simulation is similar to the previous section. K- $\varepsilon$ and RNG turbulence model was used to simulate wind flow.

\section{Verification of Numerical Results}

To ensure the accuracy of numerical results, they must be compared to a laboratory work. In this study,

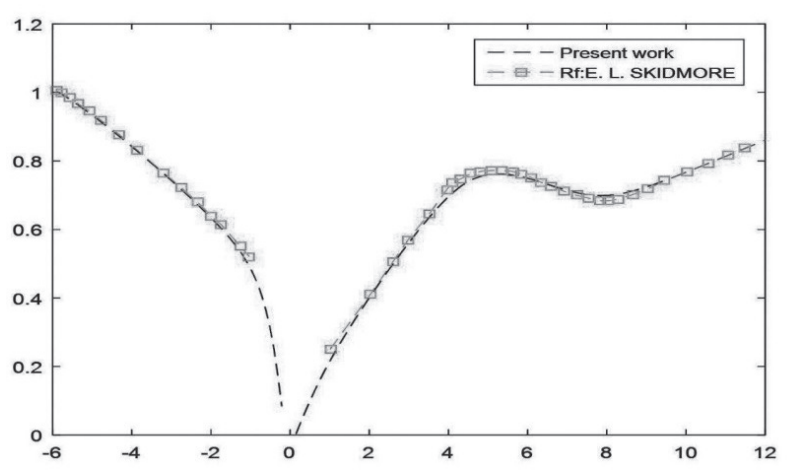

Fig. 4. Comparing the wind speed profiles in the present study with a study by Skidmore and Hagen. 


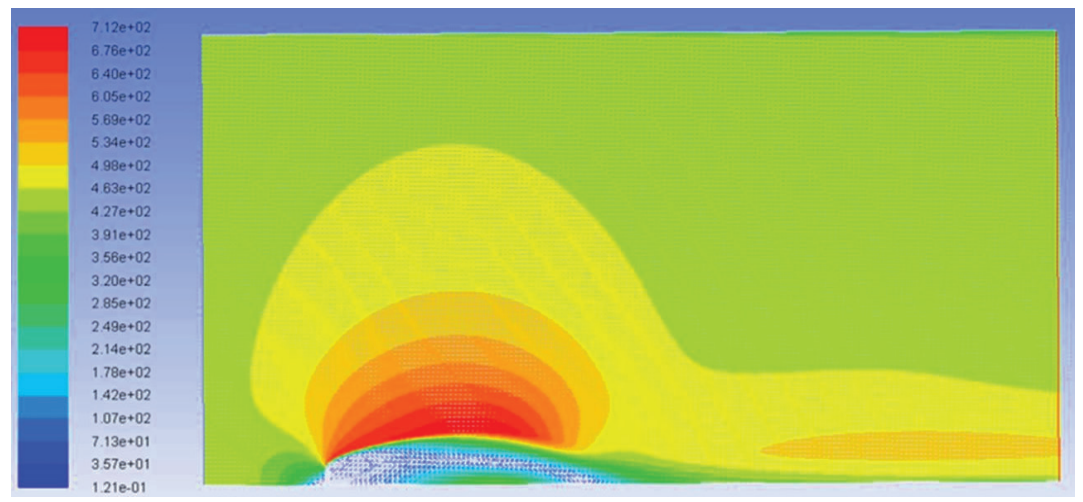

Fig. 5. Wind speed profile for a $0.083 \mathrm{~m}$ ( $2 \mathrm{~m}$ in reality) solid windbreak.

the empirical results of the study by Skidmore and Hagen were used. To this end, the wind velocity profile was drawn for a solid windbreak (height $=2.24 \mathrm{~m}$ and wind speed $=4.3 \mathrm{~m} / \mathrm{s}$ ). According to the diagram, an optimal consistency was found between the numerical results and those of Skidmore and Hagen. The relative error was reported $1.568 \%$, which is within an acceptable range. Note that a part of the mentioned error is associated with the height and length of flow in the numerical model.

\section{Results and Discussion}

According to relationship No. 1, evaporation has been found to have a direct relationship with temperature and wind velocity. It has an inverse relationship with humidity. This means that increasing temperature and wind velocity lead to increasing regional evaporation. As a result, one unit change of wind velocity creates the greatest change in evaporation compared to other parameters. We conclude that wind is the most important evaporation factor in the Chahnimeh Reservoir. Consequently, windbreaks can be used to control evaporation.
When the barrier is congested on the water surface, the air flow will pass over it. An air turbulence is created on the wind leeward due to lower pressure. Above the windbreak $(\mathrm{Z} / \mathrm{H}>1 \mathrm{Z}$ is the height above the ground), the wind is deviated upwards and airflow lines are compressed. As can be seen in Fig. 5, high wind velocity only occurs at areas above the windbreak. Wind velocity is significantly reduced behind the barrier at lower heights $(\mathrm{Z} / \mathrm{H}<1)$. This area, where the velocity is significantly reduced, is called the quiet zone. The length of this zone is usually considered between 5 and $10 \mathrm{H}$. If the wind condenses, air flow changes direction in the quiet zone, creating an eddy current. Along with the leeward after the quiet zone lies in the wake zone, where the air flow gradually recovers in line with wind velocity. The area stretches between 30 and $50 \mathrm{H}$; however, the wind almost reaches its initial velocity at distances greater than $25 \mathrm{H}$. Meanwhile, the eddy current significantly declines in the awakening area and wind flow changes to regular lines. Fig. 5 shows the wind velocity profile for a $0.083 \mathrm{~m}$ windbreak. As can be seen, an excessive increase in height has no effect on wind flow and the wind reaches its initial value.

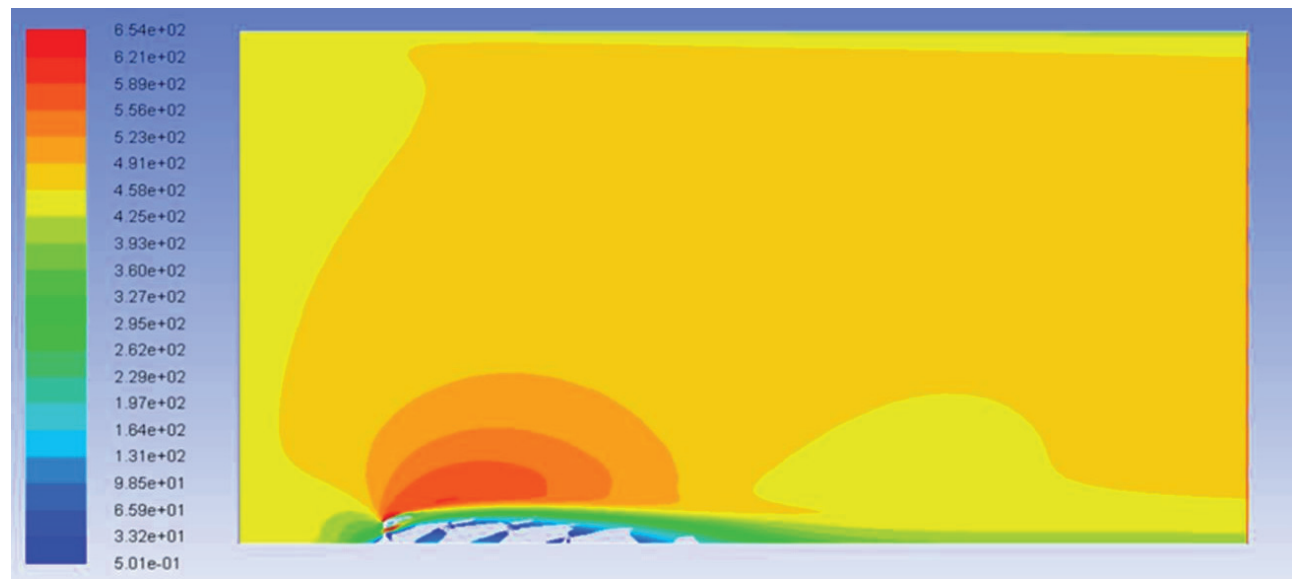

Fig. 6. Wind speed profile for a $0.083 \mathrm{~m}$ ( $2 \mathrm{~m}$ in reality) solid windbreak ( $25 \%$ casement). 
Table 1. Wind speed reduction per different windbreak heights.

\begin{tabular}{|c|c|}
\hline \multicolumn{2}{|c|}{ One Windbreak } \\
\hline Windbreak height $(\mathrm{m})$ & Wind speed reduction (\%) \\
\hline 0.083 & 30.2 \\
\hline 0.1 & 21.07 \\
\hline 0.125 & 2.47 \\
\hline 0.167 & -1.96 \\
\hline 0.208 & -1.2 \\
\hline
\end{tabular}

A decrease in windbreak density is responsible for an increase in the volume of passing air through the barrier. This results in the pressure difference between two sides of the windbreak, responsible for the increase in effective region on the leeward side. Fig. 6 shows the wind velocity profile for windbreaks with casement. Here, since the volume of wind passing through the barrier increases, the eddy current declines and a regular flow is experienced.

To determine the best windbreak height, five heights were taken into account: $0.083,0.1,0.125,0.167$, and 0.208 . To determine the wind velocity reduction, a wind speed diagram was drawn for each windbreak up to $30 \mathrm{H}$ distance after the windbreak. Accordingly, speed changes were calculated. Table 1 shows wind speed reduction at different heights. As can be seen, 0.167 and 0.208 ( 4 and $5 \mathrm{~m}$ in reality) windbreaks are responsible for the wind speed increase. These windbreaks are very

Table 2. Wind speed reduction for 0.083 and $0.1 \mathrm{~m}$ windbreak

\begin{tabular}{|c|c|c|}
\hline $\begin{array}{l}\text { Windbreak height } \\
(\mathrm{m})\end{array}$ & $\begin{array}{l}\text { Distance } \\
(\mathrm{m})\end{array}$ & $\begin{array}{l}\text { Reduced wind speed } \\
\qquad(\%)\end{array}$ \\
\hline \multirow{8}{*}{0.083} & 0.75 & 78.07017544 \\
\hline & 1 & 39.69298246 \\
\hline & 1.25 & 28.50877193 \\
\hline & 1.5 & 78.07017544 \\
\hline & 1.75 & 45.1754386 \\
\hline & 2 & 16.66666667 \\
\hline & 2.25 & 6.798245614 \\
\hline & 2.5 & 4.166666667 \\
\hline \multirow{10}{*}{0.1} & 0.75 & 75.43859649 \\
\hline & 1 & 28.72807018 \\
\hline & 1.25 & 6.798245614 \\
\hline & 1.5 & 28.72807018 \\
\hline & 1.75 & 91.88596491 \\
\hline & 2 & 25.87719298 \\
\hline & 2.25 & 8.99122807 \\
\hline & 2.5 & 1.315789474 \\
\hline & 2.75 & -3.070175439 \\
\hline & 3 & -3.070175439 \\
\hline
\end{tabular}

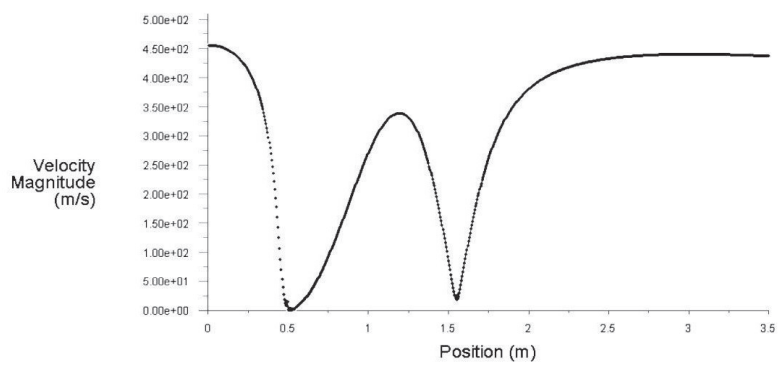

Fig. 7. Wind speed on water surface for a $0.083 \mathrm{~m}$ windbreak.

stiff. 0.083 and 0.1 ( 2 and $2.5 \mathrm{~m}$ in reality) windbreaks result in the greatest increase.

Table 2 shows the wind speed reduction up to $30 \mathrm{H}$ after the 0.083 and 0.1 windbreaks in order to select the best windbreak height. As can be seen, we are faced with wind speed increases at 2.75, 3, and more for the 0.1 windbreak. As a result, the $0.083 \mathrm{~m}$ windbreak ( $2 \mathrm{~m}$ in reality) is found to be the best windbreak for Chahnimeh Reservoir.

Fig. 7 shows the wind speed changes at water surface for the $0.083 \mathrm{~m}$ windbreak. According to the diagram, although we were faced with the gradual increase in wind speed up to $14 \mathrm{H}$, it has significantly decreased compared to the initial speed. When the wind speed reached its peak at $14 \mathrm{H}(340 \mathrm{~m} / \mathrm{s})$, it declines up to $18 \mathrm{H}$. Wind speed gradually increases after $18 \mathrm{H}$ and reaches its initial value. As expected, the minimum wind speed was seen near the windbreak at $\mathrm{H}$ after the windbreak. For the $0.083 \mathrm{~m}$ windbreak, wind speed reaches its initial value after $30 \mathrm{H}$.

To arrange the windbreaks and find the best distance, two- and three-row models were taken into account by 0.083 windbreaks. A three-row windbreak $(0.083 \mathrm{~m})$ was responsible for the greater wind speed reduction. As a result, we considered it the criterion. As the distance rises between windbreaks to $50 \mathrm{H}$, the optimal distance is achieved. The results showed that wind speed reduction scored the top at $2 \mathrm{~m}$ (73.71\%), responsible for $74.1 \%$ evaporation reduction. Also wind speed reduction and evaporation rates are similar. Therefore, $2 \mathrm{~m}$ (48 $\mathrm{m}$ in reality) was considered the most optimal distance.

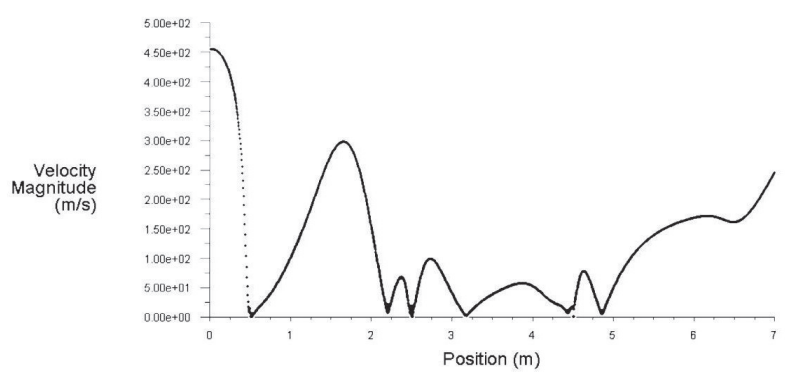

Fig. 8. Wind speed on water surface among three windbreaks (height $=0.083 \mathrm{~m}$ and distance $=2 \mathrm{~m}$ ). 
Table 3. Wind speed reduction for various porosities.

\begin{tabular}{|c|c|c|}
\hline $\begin{array}{c}\text { Windbreak height } \\
(\mathrm{m})\end{array}$ & $\begin{array}{c}\text { Porosity } \\
(\%)\end{array}$ & $\begin{array}{c}\text { Wind speed reduction } \\
(\%)\end{array}$ \\
\hline \multirow{4}{*}{0.083} & 10 & 24.1 \\
\cline { 2 - 3 } & 15 & 28.22 \\
\cline { 2 - 3 } & 20 & 37.53 \\
\cline { 2 - 3 } & 25 & 38.72 \\
\cline { 2 - 3 } & 30 & 35.86 \\
\hline
\end{tabular}

Fig. 8 shows the wind speed on water surface among three windbreaks (height $=0.083 \mathrm{~m}$ and distance $=2 \mathrm{~m}$ ). From $0.05 \mathrm{~m}$ from the windbreak to $20 \mathrm{H}$, a gradual increase in wind speed is expected. As can be seen in Fig. 8, the wind speed gradually increased. However, it is less than the initial speed $(456 \mathrm{~m} / \mathrm{s})$. Maximum speed occurs at $20 \mathrm{H}$. From $20 \mathrm{H}$ to $28 \mathrm{H}$, wind declines. From $28 \mathrm{H}$ to $30 \mathrm{H}$ where the second windbreak is located, the speed is irregular. Since the $2^{\text {nd }}$ windbreak has partially diverted the wind upwards, leeward speed reduction is greater than that of the $1^{\text {st }}$ windbreak. Slight wind reduction is seen between the $2^{\text {nd }}$ and $3^{\text {rd }}$ windbreaks. Maximum speed occurs after the $2^{\text {nd }}$ windbreak at $33 \mathrm{H}$, while the minimum happens at $40 \mathrm{H}$. After the $3^{\text {rd }}$ windbreak at $54 \mathrm{H}$, the speed gradually recovers, ultimately reaching its initial value.

Porosity is one of the most effective factors in windbreak structures. Windbreaks with casement were the innovation of our study. Casement/total area ratio shows the casement percentage. $0.083 \mathrm{~m}$ windbreak with casement was taken into account. Table 3 shows the wind speed reduction for various percentages of casement area. As can be seen, 25\% casement windbreak was responsible for the greatest wind speed reduction.

Fig. 9 shows the wind speed changes at water surface for a $0.083 \mathrm{~m}$ windbreak. According to the diagram, although we were faced with a gradual wind speed increase up to $9 \mathrm{H}$, the speed significantly declined compared to the initial speed. From $9 \mathrm{H}$ to $14 \mathrm{H}$, the speed of the wind declines. Afterward, it gradually increases until it reaches the initial speed. A comparison of Figs. 7 and 9 show that leeward speed of casement windbreak is less than that of the solid windbreak; however, wind

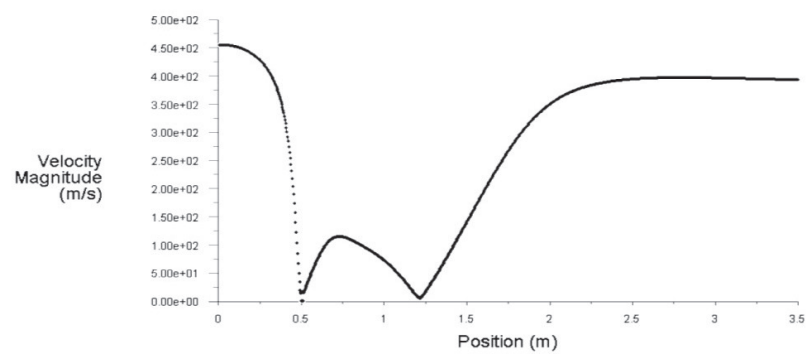

Fig. 9. Wind speed on water surface for $25 \%$ casement windbreak.
Table 4. Wind speed reduction for various casement angles

\begin{tabular}{|c|c|c|}
\hline $\begin{array}{c}\text { Windbreak height } \\
(\mathrm{m})\end{array}$ & Angle & $\begin{array}{c}\text { Reduce wind speed } \\
(\%)\end{array}$ \\
\hline \multirow{4}{*}{0.083} & 30 & 24.69 \\
\cline { 2 - 3 } & 45 & 29.51 \\
\cline { 2 - 3 } & 60 & 30.08 \\
\cline { 2 - 3 } & 90 & 30.2 \\
\hline
\end{tabular}

speed increases after reaching the minimum value. It reaches the initial value after $30 \mathrm{H}$. Less porosity is responsible for the movement of minimum wind speed toward the barrier.

The distance increased to $50 \mathrm{H}$ to determine the optimal distance. Wind speed reaches the maximum at $2.75 \mathrm{~m}(50.44 \%)$, responsible for $50.67 \%$ of evaporation reduction. Similar to the solid mode, evaporation reduction is proportional to wind speed. Therefore, $25 \%$ casement windbreaks were used with the distance of $2.75 \mathrm{~m}$ (66 $\mathrm{m}$ in reality).

The results of solid and casement windbreaks showed that windbreaks alone cannot control evaporation. However, evaporation significantly declines. To this end, diagonal windbreaks were used. If diagonal windbreaks are used in the case of being combined with other evaporation control methods such as solar panels or floating sheets, the evaporation is fully controlled. In addition to reducing wind speed, diagonal windbreaks can act as shadow structure and reduce temperature. If they are combined with floating sheets, they block the movement of sheets as a result of wind. Meanwhile, the wind declines and shadow is created. Diagonal windbreaks can also be used as solar panels. Table 4 shows the wind speed reduction for different angles. As can be seen, as the windbreak moves toward the vertical position, wind speed reduction increases. The greatest wind speed reduction was seen at 60 degrees.

In order to achieve essential efficiency, windbreaks should be located against the dominant wind. To determine the windbreak location, wind velocity data of Chahnimeh were collected. Then the data were analyzed and the dominant wind was determined, which is from the northwest. Therefore, windbreaks need to be installed along this direction.

\section{Conclusions}

In this study, the effect of wind on evaporation is investigated in a windy region on the surface of water in reservoirs. The initial analysis shows that wind is the most important factor on regional evaporation in the study area. Artificial windbreaks are used to control the wind speed on the reservoir water surface. The effect of windbreaks on evaporation reduction and wind flow was modeled. Windbreaks with various heights and distances were used to control the wind. According to 
hydrological conditions, the maximum solid windbreak efficiency is achieved when 161 solid windbreak rows are used (height $=2 \mathrm{~m}$ and distance $=48 \mathrm{~m}$ ). This leads to wind speed reduction by $73.71 \%$ and evaporation reduction by $74.1 \%$. If casement windbreaks are used, the maximum efficiency is achieved when 117 rows of windbreaks with $25 \%$ casement (distance $=66 \mathrm{~m}$ and height $=2 \mathrm{~m}$ ) are used, leading to the wind speed and evaporation reduction by $50.44 \%$ and $50.67 \%$, respectively. In both modes, windbreak length and width need to be equal, located along the northwest direction. On the other hand, the results show that windbreaks alone cannot control evaporation; however, it is very effective. If a combination of methods is being considered, such as floating sheets or solar panels, more satisfied results will be expected. Results show that a windbreak with the angle equal to 60 degrees with the horizon can be used to reduce evaporation by up to $30.08 \%$.

\section{Conflict of Interest}

All authors declare no conflict of interest.

\section{References}

1. DING J., LI H., CUO L., YI C. Water quality variation characteristics in storm water period and on weihe river time scale. Polish Journal of Environmental Studies. 26 (6), 2495, 2017.

2. YAO X., ZHANG H., LEMCKERT C., BROOK A., Schouten P. Evaporation reduction by suspended and floating covers: Overview, Modelling and Efficiency. Urban Water Security Research Alliance. 2010.

3. KARAOGLU M., SIMSEK U., TOHUMCU F., ERDEL E. Determining surface soil properties of wind erosion area of igdir-aralik and estimating the soil loss. Fresenius Environmental Bulletin. 26 (5), 3170, 2017.

4. CONG X.C., DU H.B., DAI M.X. Field measurement of shelter efficacy for installed wind fences in the open coal yard. Journal of Engineering and Industrial Aerodynamics. 117, 18, 2013.

5. SKIDMORE E.L., HAGEN L.J. Evaporation in sheltered areas as influenced by windbreak porosity. Agricultural Meteorology. 7, 363, 1970.

6. BRANDLE J.R., FINCH S. How windbreaks work. 1991.

7. HELFER F., ZHANG H., LEMCKERT C. Evaporation reduction by windbreaks: Overview, Modelling and Efficiency. Urban Water Security Research Alliance, 2009.

8. RAINE J.K., STEVENSON D.C. Wind protection by model fences in a simulated atmospheric boundary layer. Journal of Wind Engineering and Industrial Aerodynamics. 2 (2), 159, 1977.

9. WILSON J.D. On the choice of a windbreak porosity profile. Boundary-Layer Meteorology. 38 (1-2), 37, 1987.

10. HEISLER G.M., DEWALLE D.R. Effects of windbreak structure on wind flow. Agriculture, Ecosystems \& Environment. 22-23, 41, 1988.

11. CHU C., CHANG C., HUANG C., WU T., WANG C., LIU M. Windbreak protection for road vehicles against crosswind. Journal of Wind Engineering and Industrial Aerodynamics. 116, 61, 2013.

12. CLEUGH H.A. Effects of windbreaks on airflow, microclimates and crop yields. Agroforestry Systems. 41 (1), 55, 1998

13. YEH C.P., TSAI C.H., YANG R.J. An Investigation into the sheltering performance of porous windbreaks under various wind directions. Journal of Wind Engineering and Industrial Aerodynamics. 98 (10-11), 520, 2010.

14. BAJSANSKI I., STOJAKOVIC V., TEPAVCEVIC B., JAVANOVIE M., MITOV D. An application of the shark skin denticle geometry for windbreak fences design and fabrication. Journal of Bionic Engineering. 14 (3), 579, 2017.

15. KIM R.W., LEE I.B., KWON K.S., YEO U.H., LEE S.Y., LEE M.H. Design of a windbreak fence to reduce fugitive dust in open areas. Computers and Electronics in Agriculture. 2017.

16. MERCER G.N. Modelling to determine the optimal porosity of shelterbelts for the capture of agricultural spray drift. Environmental Modelling \& Software. 24 (11), 1349, 2009.

17. HONG S.W., LEE I.B., SEO I.H., KNOWN K.S., KIM T.W., ON Y.H., KIM M. Measurement and prediction of soil erosion in dry field using portable wind erosion tunnel. Biosystems Engineering. 118, 68, 2014.

18. CAMPI P., PALUMBO A.D., MASTTORILLI M. Effects of tree windbreak on microclimate and wheat productivity in a Mediterranean environment. European Journal of Agronomy. 30 (3), 220, 2009.

19. WOON-HANG S., LEE I., SEO I. Modeling and predicting wind velocity patterns for windbreak fence design. Journal of Wind Engineering and Industrial Aerodynamic. 142, 53, 2015.

20. BITOG J.P., LEE I.B., SHIN M.H., HONG S.W., HWANG H.S., SEO I.H., YOO J.I., KWON K.S., KIM Y.H., HAN J.W. Numerical simulation of an array of fences in saemangeum reclaimed land. Atmospheric Environment. 43 (30), 4612, 2009.

21. DONG Z., LUO W., QIAN G., LU P., WANG H. A wind tunnel simulation of the turbulence behind upright wind fences. Journal of Arid Environments. 74 (2), 193, 2010.

22. SPECKART S.O., PARDYJAL E.R. A method for rapidly computing windbreak flow field variables. Journal of Wind Engineering and Industrial Aerodynamics. 132, 101, 2014.

23. BITOG J.P., LEE I.B., HWANG M.H., HONG S.W., SEO I.H. A wind tunnel study on aerodynamic porosity and windbreak drag. Forest Science and Technology. 7 (1), 8, 2010.

24. LEE K.H., EHSANI R., CASTLE W.S. A Laser scanning system for estimating wind velocity reduction through tree windbreaks. Computers and Electronics in Agriculture. $\mathbf{7 3}$ (1), 1, 2010.

25. BITOG J.P., LEE I.B., HWANG H.S., SHIN M.H., HONG S.W., SEO I.H., KWON K.S., MOSTAFA, E., PANG Z. Numerical simulation study of a tree windbreak. Biosystems Engineering. 111 (1), 40, 2012.

26. WU X., ZOU X., ZHOU N., CHI S. Deceleration efficiencies of shrub windbreak in a wind tunnel. Aeolian Research. 16, 11, 2015.

27. SMITH D.M., JARVIS P.G., ODONGO J.C. Sources of water used by trees and millet in sahelian windbreak systems. Journal of Hydrology. 198 (1-4), 140, 1997.

28. GARCIA T., GUTIERREZ M., AVILA S., FRANCHINI S., HERRERA E., MESEGUER J. On the effects of 
windbreak on the aerodynamic loads over parabolic solar troughs. Applied Energy. 115, 293, 2014.

29. BARBOSA C., SEVERINO C., MATSUMOTO E., GUIJUN L., LABAKI L., LEONE M., BAEBOSA P., VATAVUK P., CAMARGO R., FORTI T. Windbreak working as barriers to high speed winds for protection of electric power transmission lines and towers. Engineering Failure Analysis. 82, 753, 2017.

30. HE Y., JONES P.J., RAYMENT, M. A Simple parameterisation of windbreak effects on wind speed reduction and resulting thermal benefits to sheep. Agricultural and Forest Meteorology. 239, 96, 2017.

31. LIN X.J., BARRINGTON S., CHOINIERE D., Prasher S. Effect of weather conditions on windbreak odour dispersion. Journal of wind engineering and industrial aerodynamics. 97 (11-12), 487, 2009.

32. VIGIAK O., STERK G., WARREN A., HAGEN L.J. Spatial modeling of wind speed around windbreaks. Catena. 52 (3-4), 273, 2003.
33. YUSAIYIN M., TANAKA N. Effect of windbreak width in wind direction on wind velocity reduction. Journal of Forestry Research. 20 (3), 199, 2009.

34. GIANNOULIS A., MISTRIOTIS A., BRIASSOULIS D. Design and analysis of the response of elastically supported wind-break panels of two different permeabilities under wind load. Biosystems Engineering. 129, 57, 2015.

35. BOURDIN P., JOHN D., WILSON. Windbreak aerodynamics: is computing fluid dynamics reliable?. Boundary- Layer Meteorology. 126 (2), 181, 2008.

36. TOWHIDI A., GHAFARI GHAHROUDI H. ANSYS FLEUNT Guideline, 1rd ed.; Cultural and Art Institute of Dybaran: Tehran, Iran, pp. 11-12, 2015 [In Persian].

37. MIANEH M. "Determining desertification in vulnerable areas of Iran based on climatic indicators using mathematical models", MSC Thesis, Islamic Azad Unievrsity, Shahr-e Ray Branch [In Persian]. 